\title{
PROMESA ACOMPLERTA
}

\author{
J. FERRATER MORA
}

Fa una vintena d'anys parlava amb el Pep Calsamiglia sobre filosofia catalana. Va sortir a la conversa, naturaiment, Joaquim Xirau, mestre de tants. Vaig dir al Pep Calsamiglia que una vegada havia escoltat Xitau dir que, malgrat la distància filosôfica que hi havia entre ell $\mathrm{i}$ Ramon 'Turró, li semblava que era una personalitat filosoifica remarcable que calia eincorporaty a la història de la filosofia catalana. Pet què no escrius unes ratlies, encara que siguin només expositòries, sobre la filosofia de Ramon Turró? em va preguntar Pep Calsamiglia. Les podriem publicar, quan sigui l'hora, en alguna revista de filosoffa catalana. Vaig escriure aleshores les pàgines que m'havia suggerit el Pep Calsamiglia, i que han restat. fins ara, inèdites. Les publico en la revista de filosofia catalana que dedica un número a la memòria de Pep Calsamiglia i d'aquesta mancra acompelixo, vint anys després, el desig itcl nostre admitat i recotdat amic.

Una de les maneres menys inadequades de definir la filosofia de Ramon Turró és la següen: resolució naturalista del problema epistemològic fonamental de Kant. Ara bé, el sfenomen primordial» que proposava Turró no era, com en les tondencies naturalistes del.segle XIX. el clima, Ia raça o «la vida», sinó un fet fisiològic dererminat: la fam. Turtó volia esbrinar «com i de quina manera hem arribat a conèixer que en les coses que poblen l'ambient en el qual vivim hi ha una cosa substantiva que no és percebuda pels sentits» ( $L a$ base trófica de la inteligencia, 1918, pàg. 14). l.allunyament de tota consciència-teflexa - fundada en la noció de l'energia específica dels sentits, de la qual havia parlat Johannes Müller - obliga a buscar dins del subjecte - un subjecte «natural»- els elements que ens poden conduir al coneixement. Es passa d'aquesta manera de l'anàlisi kantiana de la idealitat transcental a una observació empírica. Però l'observació empírica ens mostra, en primer lloc, «l'especificitat de les sensacions tròfiques». Aquestes sensacions són. en opinió de Turró, els elements sobre cls quals cal bastir el sistema del coneixement. No perquè tot $\mathrm{cl}$ coneixement, en les seves múltiples formes, sigui reduible a la fam, o sigui conseqüència del «tornaveu tròfic», sinó percluè és el seu estrat bàsic, sense el qual el coneixement no és possible. Per consegüent, la fám no és, com escriu Ramon Turró, «una im- pulsió amorfa que ens porta a ingerir aquesta classe de cossos exteriors que enomenem "aliments", sinó una suma de tendències electives que ens porten a ingerir els aliments que contenen virtualment les substàncies que cal anabolit. zar a fi de restablir la composició original de la matèria vivent $i$ que ens porta a ingerir-los d'acord amb la tasa prefixada per la nodrició mateixa» (op. cit. pàg. 63). La fam sembla ser, per consegüent, una mena d'«impuls» que sostè cls altres impulsos, peró és un impuls que porta en el seu si la possibilitat d'elecció i, en consequiència. la possibilitar d'un coneixement de la cosa excollida. Les sensacions trófiques acusen la necessitat d'una substància, però d'una substància diferenciada.

Es obvi que el pas d'aquesta nccessitat de diferenciació al coneixement planteja nombrosos problemes. Ramon Turró no els ignora pas. Per començar, posa en relleu que la sensació trófica és solament «la primera matèria sobre la qual s'ha de muntar l'objecte del coneixcment", per* què «una cosa és sentir sed i una altra cosa, ben difetent, és conèixer l'aigua amb la qual s'ha de satisfer la sed" (op. cit. pàgs. 75 i 82 ). No obstant, la distància entre coneixement intel-lectual i sensació tròfica no és ni infinita ni irreconciliable. Hi ha un pont bastit pel «quadte de les impressions» que recorden l'efecte trófic, de manera que "primer coneixem les coses per l'efecte tröfic que determinen, abans que ens sigui cone* gudes per l'aspecte espacial en què ens son pre. sentades per mitjà de la percepció externa» (op). cit. pàg. 92. També, i sobretot, Origens del co. neixement. La fam, 1912 [edició d'Edicions $62 \mathrm{i}$ «la Caixa», 1980. Cap. VII, especialment pàgs. 61 j següents). O. com diu també Ramon Turró: «No coneixem de la mateixa manera amb les impressions sensorials --que ens permeten reconèixer les ptopietats nodrimentals dels alimentsque amb les imatges sensorials --que ens permeten teconèixer els objectes-. Llur respectiu valor logic es molt diferent (el subratllat és meu). Amb les primeres reconeixem la presència de coses, de la substantivitat $\mathrm{i}$ de la realitat de les quals ens assessora la sensibilitat tròfica, mentre que amb les segones coneixem objectes que diferenciem uns dels altres, segons les diferents im. pressions determinades sobre els sentits, però de la realitat de les quals no podem dubtar perquè s'han fet relativament més representatives de la 
realitat que de l'objecte (distinció, afegetxo, clàssicament kantiana). Si en un primer estadi la intel-ligencia no hagués començat per representar.se les coses que nodreixen per mitjà de les impressions que reben els sentits, mai no podríem, en diferenciat uns objectes dels altres per la percepció externa, donar per ben establert que les nostres imatges responen a cose's que existeixen i subsisteixen independetment de les nostres imatges» (op). cit.. pàg. 107).

Veiem aquí un aspecte fonamentai del persament filosófic de Ramon Turró: el no desconèixer la distància entre sensació i representació àd. huc quan admet que la segona està basada en la primera. Això explica que la substància nodrido. ra, en ésser percebuda com a cosa exterior, no sigui ja «com ho va ser en un moment més obscur de la intel-leció, una cosa que ingresa i determi. na un efecte benèfic, sinó allò que ha de ingresar a fi de produir cal cfecte» o, si es vol, «la impres. sió que brolla del fons orgànic com una força cega $i$ coss llança cap al món extcrior. deixa de ser cega, transformant -se en incel-kectiva. quan les notes aillades que suministren els sentits propor. cionen cls clements representalius de la substància nodridora» (Cf. Els origens del coneixement. la fam. Cap. IX. parsim).

Per consegüent, la representació varia amb la cosa representada. de manera que el primitu subjectivisme de la teoria trófica cedevé un ob- jectivisme - - un objectivisme, ben entès, de caire naturalista-... Ia teoria del coneixement que va claborar Ramon Turró és, des d'aquest punt de vista, un intent de corregir, per mitjà d'una forma empirista, el subjectivisme idealistit al que pot portar l'epistemologia kantiana quan s'accentua massa el motiu transcendental en deiriment dels motius empirics. I.es raons d aquesta embestida contra el subjectivisme són per a Ramon Turró ben clares: es tracta no solameme d'establir le's bases d'una ciència solida, sino també les bases d'una societat estable. Aixo explica la insistència de 'Turró sobre el que anomenat «la disciplina mental». necessàtia cant per a la ciència com per a la sociéct. Ramon Turró parla del anial del subjectivisme. que es ef mal del nusire temps" (Cf. La disciplina mental. 1924. pìg. 24). Però en arribar aquí podem preguntarnos si cel pensament de Ramon Turró. que de priner atnuvi sxmblava exclusivament fonamentat (n) un ex:menen cientific, no estava, en deurrer ernx. deserninat, o almenys parciatment condi. cronal per exigències morals. Si és així, el seu «kinı isme» haturia estat cncara més accentuat del qux podria pensar-se, perquè, de manera no mul diferent de la del mateix Kant, hauria pres la «taí pràtrical» com orientadora de la «raó teòri(at). In punt que valdria la pena discutir amb botal calma. 